\title{
RELIGIÃO ATRÁS DAS GRADES: PLURALISMO E CONVERSÃO NOS CÁRCERES BRASILEIROS \\ RELIGION BEHIND BARS: PLURALISM AND CONVERSION IN BRAZILIAN PRISONS
}

\author{
Antonio Carlos da Rosa Silva Junior \\ acarlos_juridico@yahoo.com.br \\ Bacharel em Direito e doutorando em Ciência da Religião pela Universidade Federal de Juiz de Fora (UFJF)
}

\section{RESUMO}

O presente artigo aborda a capelania prisional a partir dos temas do pluralismo religioso e da conversão. De início traçamos algumas notas sobre a ressocializações como os tribunais entendem o papel da religião nesse processo. Finalmente, após apontarmos o histórico constitucional da consolidação da assistência religiosa como um direito,o ensaio indica as perspectivas jurídicas e fáticas de como tais temas se apresentam nos cárceres brasileiros.

Palavras-chave: Capelania prisional. Pluralismo religioso. Conversão.

\begin{abstract}
This article adresses the prison chaplaincy from the themes of religious pluralism and conversion. At first we draw some notes about rehabilitation and how courts understand the role of religion in the process. Finally, after we show the constitutional history of the consolidation of religious care as a right, the test indicates the legal and factual perspectives on how these issues are presented in Brazilian prisons.
\end{abstract}

Keywords: Prison chaplaincy. Religious pluralism. Conversion.

\section{INTRODUÇÃO}

Pensar e escrever sobre o sistema prisional é mover sobre um terreno arenoso, no qual dificilmente se trata sem o estímulo das paixões. Mesmo para o mais imparcial dos pesquisadores - se a tão propalada imparcialidade acadêmica verdadeiramente existisse - seria (quase) impraticável sondar o estado caótico dos locais destinados ao cumprimento das penas privativas de liberdade e não ser assaltado por alguma emoção. Mazela, degradação eviolência são apenas algumas palavras capazes de sintetizar a desordem e a violação dos direitos humanos nos cárceres brasileiros. 
Se esse quadro é verdade - e as estatísticas oficiais nos revelam que sim -, como cumprir o art. $1^{\circ}$ da Lei de Execução Penal (LEP - Lei no 7.210/84) para fazer com que a execução da pena promova "condições para a harmônica integração social do condenado". E, convém desde logo esclarecer, optamos pelo

\begin{abstract}
“[...] termo ressocialização - a 'tratamento', 'reabilitação' e 'reintegração social', por exemplo - por três motivos principais: i) a terminologia empregada em nada altera o conteúdo tratado; ii) esse é o vocábulo mais utilizado pelos estudiosos quando escrevem sobre o fenômeno, restando por isso consagrado; e iii) a adoção de um padrão evita desencontros terminológicos." (SILVA JUNIOR, 2013a, p. 19-20) (grifo no original).
\end{abstract}

Conforme expõe Bitencourt, a criminologia moderna procura, balizada na promoção da justiça humana, o retorno de um infrator recuperado para o seio social (2004, p. 37). E, como assevera Alvino Sá (2007), doutor em Psicologia Clínica, a propagação de uma reforma moral seria imprescindível para a exitosa reinserção. É com base nessa perspectiva que se defende a importância da religião no processo de ressocialização, quiçá como único veículo, per si, capaz de propiciar a propalada reforma moral (ADORNO, 2004; MIRABETE, 1997, p. 82; NUNES, 2009, p. 39-40; TOMÉ, [s.d.]).

Nesse contexto, a mais alta Corte do país decidiu, por ocasião do Recurso Extraordinário (RE) no 92916/PR, no sentido de que "a justiça deve estimular no criminoso, notadamente o primário e recuperável, a prática da religião, por causa do seu conteúdo pedagógico". Essa interpretação, inclusive, foi acompanhada pelo Tribunal de Justiça do Estado de Minas Gerais (TJMG) no Recurso em Agravo (RAg) no 1.0000.00.240952-2/000(1), para o qual a religião se faz "necessária e imprescindível na reeducação do condenado, constituindo um dos fatores decisivos na ressocialização e reinserção deste na convivência com a sociedade".

Razão disso, dentre as várias possibilidades de análise das religiões nos presídios, debruçar-nos-emos sob uma perspectiva jurídico-antropológica nos temários do pluralismo religioso e da conversão, inserindo uma avaliação tanto das normas que regulam a assistência religiosa nos presídios quanto da conjuntura fática sobre as quais estas normas repousam.

Antes, porém, façamos uma breve exposição sobre a consolidação da assistência religiosa no contexto constitucional, alcançando o status atual de ser assegurada como um direito.

\title{
UM BREVE HISTÓRICO DA ASSISTÊNCIA RELIGIOSA NAS CONSTITUIÇÕES
}

A primeira Constituição do Brasil a tratar da assistência religiosa foi a de 1934, que, em seu artigo 113, item 6, dispunha:

"Sempre que solicitada, será permitida a assistência religiosa nas expedições militares, nos hospitais, nas penitenciárias e em outros estabelecimentos oficiais, sem ônus para os cofres públicos, nem constrangimento ou coação dos assistidos. Nas expedições militares a assistência religiosa só poderá ser exercida por sacerdotes brasileiros natos.”

A Carta seguinte, de 1937, não arrolou esse direito de forma expressa. Contudo, indicou que o rol dos direitos e garantias individuais (art. 122) não era taxativo, pois poder-se-ia acrescer outros que decorressem "dos princípios 
consignados na Constituição" (art. 123), tal como o exercício público e livre do culto (art. 122, $4^{\circ}$ ). Na próxima Constituição, a de 1946, constou, no art. $141, \S 9^{\circ}$, que

"Sem constrangimento dos favorecidos, será prestada por brasileiro (art. $129, \mathrm{n}_{\mathrm{s}}^{\mathrm{o}}$ I e II) [nato] assistência religiosa às forças armadas e, quando solicitada pelos interessados ou seus representantes legais, também nos estabelecimentos de internação coletiva."

A Constituição de 1967 , por sua vez, no art. $150, \S 7^{\circ}$, assegurou a prestação da assistência religiosa em termos muito semelhantes à de 1946. Diferiu apenas para constar que a mesma deveria ser feita "nos termos da lei" e por brasileiro - sem diferenciar entre nato ou naturalizado -, além de estender seu exercício às forças auxiliares. Somente enfatizando o caráter de "não obrigatoriedade" (art. 153, $\S 7^{\circ}$ ), a Emenda Constitucional n 1 de 1969, introduzida pelo Ato Institucional no 5 (AI-5), tem redação similar à da Carta de 1967.

A seu turno, a Constituição da República Federativa do Brasil de 1988, hoje vigente, em seu art. 5\%, VII, dispõe que "é assegurada, nos termos da lei, a prestação de assistência religiosa nas entidades civis e militares de internação coletiva". Esse direito é considerado uma cláusula pétrea (CRFB/1988, art. 60, $\left.\S 4^{\circ}, I V\right)$, o que equivale a dizer que, no atual ordenamento jurídico, inexiste a possibilidade de sua supressão.

Dito isso, consideramos que nosso quadro constitucional merece uma interpretação, inclusive a partir dos dispositivos anteriores, que nos servem de balizamento histórico para aclaramento de sentido. Pois bem.

Somente em 1934, na ordem jurídica máxima (a Constituição), foi "permitida" a assistência religiosa. Vemos, pois, que se tratava apenas de uma permissão estatal, e não de asseguramento, o que viabiliza inferir que o Estado, à época, não a caracterizava como algo de relevância ímpar. Ademais, por ter sido promulgada pouco depois da $1^{\mathrm{a}}$ Guerra Mundial (1914-1918), e visando resguardar o patriotismo nas expedições militares, nesse caso a assistência deveria ser "exercida por sacerdotes brasileiros natos". E, frise-se, por sacerdotes, o que nos remete à noção de que apenas a pessoa com formação eclesiástica teria permissão para exercê-la. Por fim, a assistência não poderia acarretar ônus para os cofres públicos.

Depois de a Constituição de 1937 deixar margem de dúvidas quanto à pertinência e abrangência desse direito, a de 1946 inovou ao excluir a obrigatoriedade de a assistência ser feita por sacerdote, embora continuasse a consignar a necessidade de que fosse prestada por brasileiros natos.

As modificações introduzidas pela Carta de 1967 e pela Emenda de 1969 inovaram em viabilizar que brasileiros naturalizados também prestassem a assistência, atribuindo à lei a regulamentação desse direito.

Noutro passo, a atual ordem constitucional, inaugurada em 1988, já não apenas "permite" a assistência religiosa, mas a "assegura", revelando o reconhecimento de sua importância. Demais disso, mantém o não constrangimento, pois toda pessoa tem garantida a inviolabilidade de consciência e crença (art. $5^{\circ}, \mathrm{VI}$ ).

Outrossim, embora traga em seu texto a expressão "nos termos da lei” - e isso significa que as normas infraconstitucionais balizarão o conteúdo do comando magno -, entendemos que a normatização, diante da interpretação histórica da consagração desse direito no plano constitucional, não pode proibir que leigos prestem a assistência (embora seja razoável que se exija a filiação a alguma instituição), nem mesmo que estrangeiros o façam. 
Feitas essas digressões, impende registrar que, visando dar concretude ao direito constitucionalmente assegurado, entrou em vigor a Lei ${ }^{\circ}$ 9.982/2000, que "dispõe sobre a prestação de assistência religiosa nas entidades hospitalares públicas e privadas, bem como nos estabelecimentos prisionais civis e militares". Regulamentando a questão, vigora atualmente a Resolução $\mathrm{n}^{\circ} 8$ do Conselho Nacional de Política Criminal e Penitenciária (CNPCP), que visa "estabelecer [...] diretrizes para a assistência religiosa nos estabelecimentos prisionais". E é sobre os dispositivos dessa Resolução que nos ateremos para analisar os temários aqui propostos.

\section{APONTAMENTOS SOBRE O PLURALISMO RELIGIOSO}

A Resolução n ${ }^{\circ} 8 / 2011$ do CNPCP instituiu, em seu art. $7^{\circ}$, como dever "das organizações que prestam assistência religiosa, bem como de seus representantes: I - agir de forma cooperativa com as demais denominações religiosas".

A disposição acima parece querer encontrar guarida no encaminhamento brasileiro para a diversidade religiosa, que,

“[...] como apontam os dados atuais e as projeções demográficas, está se dando principalmente pela aproximação dos percentuais católicos e evangélicos (com o fim da hegemonia católica), complementado pela presença dos sem-religião e um relativo aumento do espiritismo e das 'outras religiosidades'.” (CAMURÇA, 2013, p. 70) (grifos no original).

Esse novo dimensionamento do campo religioso nacional, marcado pela pluralização cada vez mais evidente, pode dar vazão a uma interpretação de inter-religiosidade no espaço público, com foco no diálogo e no ecumenismo. Isso pode ser constatado, inclusive, pela "preferência a atividades ecumênicas" apregoada pela normatização catarinense (SANTA CATARINA, 2011, art. 32). Contudo, apesar dos desafios de convivência não violenta entre as diversas concepções morais e filosóficas na sociedade hodierna, Mariz defende que pensemos um estado republicano e democrático a partir, também, da reflexão "sobre como convivem as diversas religiões que, por vezes, possuem valores e práticas não apenas diferentes, mas conflitantes.” (2011, p. 270-271).

Essa aproximação entre religião e violência pode ser vislumbrada, por exemplo, no espaço público do Rio de Janeiro. Segundo Leite, embora antes dominado pelo catolicismo, houve uma profusão de novos discursos religiosos, como de espíritas e evangélicos, estes últimos dotados "de significativa autoridade moral frente aos traficantes em suas atividades de evangelização nas favelas e nos presídios." (2009, p. 211) No mesmo passo, corroborando as imbricações do Estado com as Igrejas para a solução dos problemas sociais franceses, Portier aponta que nas prisões, "apesar das resistências locais, a administração se coloca cada vez mais disposta aos pedidos dos crentes" de todas as matrizes $(2010$, p. 43$)$.

E aqui nos é importante citar uma pesquisa desenvolvida por Giumbelli (2013) e que nos revela algumas possibilidades de configuração de espaços religiosos em instituições públicas a partir da cidade de Porto Alegre, no Rio Grande do Sul. É que embora a proposta inicial de mudanças na capela católica existente no Hospital das Clínicas se encaminhasse para a criação de um espaço ecumênico, em momento posterior se advogava por um "espaço de espiritualidade", marcado pela desinstitucionalização religiosa e no qual não haveria 
qualquer tipo de atendimento religioso, vedando-se possibilidades cúlticas e abarcando apenas a contemplação. Houve, ainda, o argumento de, em não se abolindo a capela, criarem-se outros espaços no hospital.

Ocorre que a "demanda inter-religiosa por um 'uso ecumênico da capela" (p. 41) foi retomada pelo Grupo de Diálogo Inter-Religioso de Porto Alegre (DIR-POA), reconhecido, por uma lei municipal de 2008, como entidade que visa “"prestar assistência espiritual e litúrgica celebrativa em eventos oficiais e não oficiais', autorizando convites realizados por 'órgãos públicos ou privados'.” (p.41) Esse viés hermenêutico e prático da relação Estado-religião passa pela proposta da Procuradoria Regional dos Direitos do Cidadão, que, enquanto órgão do Ministério Público Federal, foi convidado, em 2010, a mediar o conflito. A Procuradoria, em 2012, emitiu Recomendação para que a capela tivesse um uso inter-religioso, apregoando que uma de suas paredes não apresentasse qualquer imagem de dada religião específica (p. 44).

Sintetizada a pesquisa giumbelliana, e retomando a análise normativa da capelania prisional, a qual, como vimos, exige que os agentes religiosos ajam "de forma cooperativa com as demais denominações", ela deve ser interpretada de modo a não violar a liberdade de crença, inclusive porque a mesma norma assevera que "o conteúdo da prática religiosa deverá ser definido pelo grupo religioso e pelas pessoas presas" (art. $\left.1^{\circ}, \mathrm{VI}\right)$. Defendemos, pois, ser

"Válida a cooperação impositiva, tão somente, nas questões de ordem procedimental (dentre outras, respeitar os locais, dias e horários disponibilizados para cada religião) que não forem contrárias à crença de cada instituição." (SILVA JUNIOR, 2013a, p. 31).

É que há, por certo, vertentes cristãs que validam o ecumenismo e o diálogo inter-religioso (a exemplo de setores anglicanos, luteranos e metodistas). Contudo, a imensa maioria dos protestantes históricos, como batistas e presbiterianos, e dos pentecostais, como os assembleianos, rechaçam essas posturas em prol da defesa do exclusivismo cristão, tanto em relação à detença da verdade religiosa quanto à soteriologia (salvação apenas em função da morte vicária de Cristo).

Tal constatação pode ser verificada, inclusive, pelas religiões e denominações que integram o DIR-POA, que iniciou suas atividades em 1996

“[...] com a presença de um padre católico, um rabino e uma liderança muçulmana; atualmente, seu blog lista representantes da Igreja Anglicana, da Igreja Luterana (IECLB), do zen budismo, do espiritismo, da fé baha'i, do islã, do judaísmo e de cultos afro-brasileiros." (GIUMBELLI, 2013, p. 41).

No caso prisional, a imposição normativa se revela ainda mais desmedida se considerarmos que, ao menos no sistema socioeducativo, os evangélicos estão em $94 \%$ das unidades do país, representando $73,4 \%$ de todas as instituições religiosas que nelas atuam (SIMÕES, 2010, p. 100 e 105, respectivamente). Outrossim, matrizes afro, quando não completamente ausentes, têm atuações ínfimas:

"Há também, segundo as internas, manifestações religiosas informais individuais não cristãs como de espíritas, budistas, místicas e da Igreja Messiânica. Cabe ressaltar ainda que, na PFDF [Penitenciária Feminina do Distrito Federal], algumas internas não têm religião. Em relação às práticas das religiões afro-brasileiras como o candomblé e a umbanda, não encontrei nenhum indício da sua presença na penitenciária. Segundo o relatado por todas as internas que entrevistei e pelas agentes penitenciárias, essas práticas religiosas não fazem parte do cotidiano prisional.” (VARGAS, 2005, p. 32). 
Ademais, ainda que não haja o mesmo levantamento em relação à presença religiosa nos presídios comuns, já há inúmeros casos de unidades prisionais que contam com as chamadas "celas evangélicas", que abrigam reclusos dessa vertente e servem, também, para a proteção de estupradores e outros detentos jurados de morte (LOBO, 2005, p. 27).

Ainda, a Revista Comunicações do ISER, no número 61, trouxe noções estruturadas sobre como seriam os trabalhos assistenciais de umbandistas (PINTO, 2005), metodistas (MACHADO, 2005), assembleianos (NASCIMENTO, 2005) e batistas (BATISTA, 2005), ou mesmo sobre as interfaces entre católicos e evangélicos (LOBO, 2005).

Os umbandistas, por um lado, dizem não enfatizar a questão religiosa, mas tratar de direitos humanos, cidadania, família e ressocialização; segundo eles, "temos clareza de que muitos se envolvem de novo com a religião [dentro do presídio] somente pela ociosidade. Pensam: 'Estou ocioso. O que me oferecerem está bom. Ou picolé ou pimenta, eu vou pegar'.” (PINTO, 2005, p. 53).

Lado outro, em síntese, os evangélicos mencionados divergem, nalgum sentido, entre si. Os metodistas reforçam sua esteira na antropologia de John Wesley e buscam entender o preso como “"objeto' de nossa evangelização" e "evangelizador" dos que estão nas igrejas, "pois traz no rosto [...] o enorme fosso social que separa as pessoas neste país." (MACHADO, 2005, p. 57) Os assembleianos visam a preparação do preso, com cursos teológicos e profissionalizantes, bem como fornecem "um sistema chamado de 'gabinete pastoral', onde nós trabalhamos mais o lado psíquico da pessoa." (NASCIMENTO, 2005, p. 60-61). Finalmente, segundo os batistas,

\footnotetext{
"Trabalhamos com assistência religiosa, que é nosso objetivo maior, ou seja, levar a evangelização à população carcerária de nosso Estado. Através dessa evangelização, buscar um reencontro com eles mesmos, através da autoestima, um reencontro com Deus e, consequentemente, a valorização moral, que eles perdem ao assumir a identidade de marginalizado. Pois quando eles são considerados marginais, são também ética e socialmente marginalizados. Então, quando eles entram no sistema, perdem um pouco de sua identidade como seres humanos. Eles ganham um registro geral, que é um número, e muitos até nem se conhecem entre si, senão pelo número. Eles têm sempre que estar com o número na ponta da língua pra poder receber qualquer assistência." (BATISTA, 2005, p. 63).
}

Assim sendo, dada à multiplicidade de interpretações da realidade prisional, exigir a cooperação religiosa em matérias confessionais e cúlticas acaba por, em nome da defesa da laicidade, do ecumenismo e da inter-religiosidade, violar a identidade da maioria das igrejas cristãs.

\section{CONVERSÃO NOS CÁRCERES}

A prática do proselitismo é expediente vedado no art. $1^{\circ}$, II, da aludida Resolução. Como a palavra é plurívoca e a norma não trata de balizá-la, cabe ao intérprete fazê-lo. Nesse sentido, tomando como referência os parâmetros constitucionais vigentes, caso se trate de impedir a disputa agressiva por novos fiéis ou o uso de subterfúgios não éticos (como o constrangimento) à mudança de religião, acertou a norma.

Contudo, caso se queira proibir a realização de doutrinação ou catequese, ou mesmo o empenho no anúncio de uma mensagem de conversão reli- 

Humanos, da qual o Brasil é signatário:

\begin{abstract}
"Todo ser humano tem direito à liberdade de pensamento, consciência e religião; este direito inclui a liberdade de mudar de religião ou crença e a liberdade de manifestar essa religião ou crença, pelo ensino, pela prática, pelo culto e pela observância, em público ou em particular." (ORGANIZAÇÃO DAS NAÇÕES UNIDAS).
\end{abstract}

De tal modo, impedir o empenho e o zelo na pregação acabaria minimizando as possibilidades para o exercício do direito à mudança de religião (art. $1^{\circ}, \mathrm{V}$, da própria Resolução). Àquele que, voluntariamente - lembremos que a imposição de se assistir a qualquer evento dessa natureza é inconstitucional -, decide ouvir um anúncio religioso deve ser garantido o direito de escutar acerca da faculdade de conversão.

Há, inclusive, decisão do Tribunal de Justiça do Rio Grande do Sul (TJRS) sobre o batismo fora da prisão, prática adotada pelas matrizes cristãs como manifestação pública da fé do convertido. In casu, decisão proferida no Agravo em Execução (AgE) n ${ }^{0} 70050784545$, confirmou sentença que

“[...] indeferiu ao apenado autorização de saída do presídio para que fosse realizada sua cerimônia de batismo, perante a Igreja Assembleia de Deus, a ser efetuada nas margens do rio Taquari, entendendo ser o pleito incompatível com o regime de cumprimento de pena do réu (fechado).”

E é nesse temário da conversão que encontramos uma maior profusão de estudos sobre a religião no sistema prisional. Berger e Luckmann (2003), por exemplo, encaram a conversão como uma ruptura biográfica que visa a reconstrução da realidade - tratar-se-ia de um clássico exemplo de alternação, em que há mudanças quase totais. Nesse passo, a conversão é tida como "uma transformação radical do viver", "um processo que promove a ressignificação de práticas, bens e, sobretudo, de representações” (SCHELIGA, 2005, p. 81).

De plano, convém notar que esse processo ocorrido intra muros deve ser analisado sob duas perspectivas:

“[...] em uma dimensão individual (Mafra, 2000), a conversão aparece como recurso linguístico da mulher aprisionada para reorganizar a própria biografia após o momento dramático do aprisionamento. Por outro lado, em uma dimensão coletiva - no que se refere ao grupo ao qual o sujeito adere - a conversão está configurando redefinições de fronteiras e reelaborações simbólicas tanto para os novos convertidos quanto para os convertedores, em função do jogo interacional que os atores sociais estão promovendo." (RODRIGUES, 2005, p. 16).

Assim, uma primeira questão a ser examinada é verificar se todas as matrizes atuantes nos presídios visam à conversão dos detidos. Enquanto Lobo apregoa que os "católicos, diferentemente dos evangélicos, fazem assistência religiosa sem pregar conversão e reagem criticamente ao avanço das igrejas evangélicas e às suas práticas proselitistas" (2005, p. 23), Vargas, sem distinguir as religiões, afirma que "o papel e o objetivo principal do seu trabalho, dentro da penitenciária, são a evangelização e a conversão religiosa” (2005, p. 34). Contudo,

"[...] de se notar que nem mesmo a CNBB possui um posicionamento firmado sobre qual a melhor perspectiva teológica quando o assunto é o trabalho com os presos. As vertentes das 'salvações' pessoal e estrutural se digladiam por um 'lugar ao sol' entre os bispos, o que, por si só, nos revela a complexidade já no prisma teórico.” (SILVA JUNIOR, 2013b, p. 26). 
Além disso, é importante perceber uma ênfase na conversão evangélica, notadamente pentecostal. É que "a visibilidade dos pentecostais é percebida não apenas pela expressividade numérica, mas também pelo comportamento e pela forma de falar e de se vestir" (LOBO, 2005, p. 22), sendo certo que isso faz os "detentos de confissão pentecostal serem considerados pelos demais funcionários, bem como pelos detentos, como mais 'calmos', 'obedientes' e, supostamente, mais aptos para a ressocialização" (SCHELIGA, 2005, p. 82). Ademais, é (quase) uníssono o discurso da administração prisional no sentido de que os presos convertidos ao Evangelho gerariam menos conflitos que os demais (LOBO, 2005, p. 22; SCHELIGA, 2005, p. 84; e VARGAS, 2005, p. 33).

$\mathrm{E}$ as interpretações sobre o resultado desse discurso variam. Enquanto alguns asseveram que a pressão do sistema sobre os presos convertidos "é, de certa forma, amenizada" (LOBO, 2005, p. 26), outros anotam que estes sentem sofrer preconceito tanto dos demais presos quanto dos funcionários da instituição (SCHELIGA, 2005, p. 78).

"[...] ser crente na cadeia significa estar sempre na berlinda, sujeito ao descrédito por um deslize qualquer, por uma palavra ou um gesto. É a expressão mais acabada de uma identidade mutilada na possibilidade de representar papeis diversos ao religioso.” (DIAS, 2005, p. 50).

De tal modo, e certamente difícil precisar em quais casos a conversão se processaria, já que, para uma interna, "Tem muita gente que se escuda atrás da Bíblia, tipo um falso profeta, que fala de Deus, mas a mente está virada para o crime" (VARGAS, 2005, p. 38). Nesse quadro, a falsa conversão "seria o resultado de uma tentativa de "enganar' ou de suprir suas diversas "carências" (SCHELIGA, 2005, p. 75).

\section{CONSIDERAÇÕES FINAIS}

Nossa proposta, neste breve artigo, foi entabular uma reflexão jurídico-antropológica da capelania prisional a partir de duas de suas nuances, quais sejam, o pluralismo religioso e a conversão. Para tanto, recorremos aos dispositivos normativos que regulam a assistência religiosa nestes espaços como base para a identificação das atuações dos religiosos nos presídios.

Outrossim, através de nossa breve inserção nestes temas foi possível perceber diferentes - e por vezes destoantes - articulações. No caso do pluralismo, há os que apregoam a prática ecumênica, enquanto outros grupos se destacam pelo exclusivismo. Quanto à conversão, demos ênfase à sua conjugação coletiva, notadamente a articulando à atuação dos grupos religiosos e ao seu impacto no ambiente carcerário.

Finalmente, é necessário registrar que várias outras problematizações acerca da capelania prisional seriam possíveis, tais comoo sincretismo e as porosidades entre as matrizes religiosas. Ainda assim ansiamos ter contribuído para um entendimento aprimorado da assistência religiosa no contexto de encarceramento.

\section{REFERENCIAS}

ADORNO, Rodrigo dos Santos. Uma análise crítica à execução penal: a partir do estudo de uma penitenciária no Rio Grande do Sul. Jus Navigandi, Teresina, a. 9, n. 288, 21 abr. 2004. Disponível em: <http://jus.com.br/revista/ texto/5115/uma-analise-critica-a-execucao-penal>. Acesso em: 21 set. 2007. 
BATISTA, Adenice Barreto. O trabalho dos batistas nas prisões. Revista Comunicações do ISER. n. 61, p. 63-67, 2005. (Religiões e Prisões).

BERGER, Peter; LUCKMANN, Thomas. A construção social da realidade. Tratado de Sociologia do conhecimento. 23. ed. Tradução de Floriano de Souza Fernandes. Petrópolis: Vozes, 2003.

BITENCOURT, Cezar Roberto. Falência da pena de prisão: Causas e alternativas. 3. ed. São Paulo: Saraiva, 2004.

BRASIL. Conselho Nacional de Política Criminal e Penitenciária. Resolução $\mathrm{n}^{\mathrm{o}} 8$, de 09 de novembro de 2011. Disponível em: <http://www.criminal.caop. mp.pr.gov.br/arquivos/File/ExecucaoPenal/CNPCP/2011resolucaoCNPCP08. pdf>. Acesso em: 17 jun. 2014.

. Constituição da República dos Estados Unidos do Brasil de 1934.

Disponível em: <http://www.planalto.gov.br>. Acesso em: 02 mar. 2013.

. Constituição da República dos Estados Unidos do Brasil de 1937.

Disponível em: <http://www.planalto.gov.br>. Acesso em: 02 mar. 2013.

. Constituição da República dos Estados Unidos do Brasil de 1946.

Disponível em: <http://www.planalto.gov.br>. Acesso em: 02 mar. 2013.

. Constituição da República Federativa do Brasil de 1967. Disponível em: <http://www.planalto.gov.br>. Acesso em: 02 mar. 2013.

. Constituição da República Federativa do Brasil de 1988. Disponível em: <http://www.planalto.gov.br>. Acesso em: 14 fev. 2013.

. Emenda Constitucional $n^{\circ} 1$, de 17 de outubro de 1969. Disponível em: <http://www.planalto.gov.br>. Acesso em: 02 mar. 2013.

Lei de Execução Penal. Lei no 7.210/1984, de 11 de julho de 1984. Disponível em: <https://www.planalto.gov.br>. Acesso em: 14 fev. 2013.

. Lei no 9.982/2000, de 14 de julho de 2000. Disponível em: <http:// www.planalto.gov.br>. Acesso em: 14 fev. 2013.

. Supremo Tribunal Federal. Recurso Extraordinário n ${ }^{\circ}$ 92916/PR. Primeira Turma. Rel. Min. Antonio Neder, j. 19.05.1981, DJ 26.06.1981. Disponível em: <http://www.stf.jus.br>. Acesso em: 21 set. 2007.

CAMURÇA, Marcelo Ayres. O Brasil religioso que emerge do Censo de 2010: consolidações, tendências e perplexidades. In: MENEZES, Renata; TEIXEIRA, Faustino (Orgs.). Religiões em movimento: o Censo de 2010. Petrópolis: Vozes, 2013.

DIAS, Camila Caldeira Nunes. Evangélicos no cárcere: representação de um papel desacreditado. In: BICCA, Alessandro, STEIL, Carlos Alberto (Orgs.). Religião e prisão. Revista Debates do NER. UFCH/UFRGS. Programa de Pós-Graduação em Antropologia Social. Ano 6, n. 8, p. 39-55, jul./dez, 2005.

GIUMBELLI, Emerson. O que é um ambiente laico? Espaços (inter)religiosos em instituições públicas. Cultura y Religión - Revista de Sociedades en Transición, v. VII, n. 2, p. 32-47, 2013.

LEITE, Márcia Pereira. Religião e política no espaço público: moradores de favelas contra a violência e por justiça. In: ALMEIDA, Ronaldo de; MAFRA, Clara (Orgs.). Religiões e cidades: Rio de Janeiro e São Paulo. São Paulo:

Terceiro Nome, p. 207-228, 2009.

LOBO, Edileuza Santana. Católicos e evangélicos em prisões do Rio de Janeiro. Revista Comunicações do ISER, n. 61, p. 22-29, 2005. (Religiões e Prisões).

MACHADO, Edvandro. Missão metodista nas prisões. Revista Comunicações do ISER, n. 61, p. 57-59, 2005. (Religiões e Prisões).

MARIZ, Cecília. Algumas reflexões sobre religião e luta pela cidadania. In: ANDRADE, Péricles; Burity, Joanildo (Orgs.). Religião e Cidadania. São Cristóvão: Editora UFS; Recife: Fundação Joaquim Nabuco, p. 263-272, 2011. 
MINAS GERAIS. Tribunal de Justiça do Estado de Minas Gerais. Recurso de Agravo n ${ }^{\circ}$ 1.0000.00.240952-2/000(1). Terceira Câmara Criminal. Rel. Des. Odilon Ferreira, j. 05.02.2002, DJ 20.02.2002. Disponível em: <http://www. tjmg.jus.br>. Acesso em: 21 set. 2007.

MIRABETE, Júlio Fabrini. Execução Penal: Comentários à Lei n ${ }^{\circ} 7.210$, de 11-7-84. 8. ed., rev. e atual., por Renato N. Fabrini, até agosto de 1997. São Paulo: Atlas, 1997.

NASCIMENTO, Vicente de Paulo. Assembleia de Deus: trabalho com internos e famílias. Revista Comunicações do ISER, n. 61, p. 60-62, 2005. (Religiões e Prisões).

NUNES, Adeildo. Da execução penal. Rio de Janeiro: Forense, 2009. ORGANIZAÇÃO DAS NAÇÕES UNIDAS. Declaração Universal dos Direitos Humanos. Disponível em: <http://unicrio.org.br/img/DeclU_D_ HumanosVersoInternet.pdf>. Acesso em: 14 fev. 2013.

PINTO, Flávia. A Casa do Perdão: resistências e estímulos aos umbandistas. Revista Comunicações do ISER, n. 61, p. 53-56, 2005. (Religiões e Prisões). PORTIER, Philippe. Regulação estatal da religião na França (1880-2008): ensaio de periodização. REVER - Revista de Estudos da Religião, p. 24-47, set., 2010.

RIO GRANDE DO SUL. Tribunal de Justiça do Estado do Rio Grande do Sul. Agravo em Execução no 70050784545 . Segunda Câmara Criminal. Rel. Des. José Antônio Cidade Pitrez, j. 11.10.2012. Disponível em: <http:// www. tjrs.jus.br>. Acesso em: 03 mar. 2013.

RODRIGUES, Gilse Elisa. Transgressão, controle social e religião: um estudo antropológico sobre práticas religiosas na penitenciária feminina do Estado do Rio Grande do Sul. In: BICCA, Alessandro, STEIL, Carlos Alberto (Orgs.).

Religião e prisão. Revista Debates do NER. UFCH/UFRGS. Programa de PósGraduação em Antropologia Social, a 6, n. 8, p. 9-20, jul./dez, 2005.

SÁ, Alvino Augusto de. Criminologia clínica e psicologia criminal. São Paulo: RT, 2007.

SANTA CATARINA. Lei Complementar n ${ }^{\circ}$ 529, de 17 de janeiro de 2011. Disponível em: <https://www.deap.sc.gov.br>. Acesso em: 22 set. 2014.

SILVA JUNIOR, Antonio Carlos da Rosa. Deus na prisão: uma análise jurídica, sociológica e teológica da capelania prisional. Rio de Janeiro: Betel, 2013.

. Recuperação religiosa de presos: conversão moral e pluralismo religioso na APAC. Dissertação. Programa de Pós-Graduação em Ciência da Religião, Universidade Federal de Juiz de Fora, Juiz de Fora, 2013.

SIMÕES, Pedro (Org.). Filhos de Deus: assistência religiosa no sistema socioeducativo. Rio de Janeiro: ISER, 2010.

SCHELIGA, Eva Lenita. Trajetórias religiosas e experiências prisionais: a conversão em uma instituição penal. Revista Comunicações do ISER, n. 61, p. 75-85, 2005. (Religiões e Prisões).

TOMÉ, Fernanda Terezinha. A influência da religião na ressocialização de detentos no presídio regional de Santa Maria - RS. Disponível em: $<$ http:// www.ufsm.br/direito/artigos/execucao-penal/influencia_religiao.htm>. Acesso em: 24 abr. 2008.

VARGAS, Laura Ordóñez. Religiosidade: mecanismo de sobrevivência na penitenciária feminina do Distrito Federal. Revista Comunicações do ISER, n. 61, p. 30-39, 2005. (Religiões e Prisões). 